\title{
ANÁLISE DE MARKET-SHARE E FONTES DE VARIAÇÃO DAS EXPORTAÇÕES BRASILEIRAS DE SOJA ${ }^{1}$
}

\author{
Adelson Martins Figueiredo ${ }^{2}$ \\ Maurinho Luiz dos Santos ${ }^{3}$ \\ Viviani Silva Lírio ${ }^{4}$
}

\begin{abstract}
Resumo - O objetivo deste trabalho é determinar os fatores que explicam a alteração da participação da agroindústria brasileira de soja no comércio internacional. Particularmente, pretende-se analisar a competitividade brasileira nas exportações de cada segmento da agroindústria de soja. Para isso, utilizou-se o modelo Constant-Market-Share (CMS), por meio do qual foram computadas as discrepâncias na variação potencial e efetiva das exportações brasileiras de grão, farelo e óleo, desagregando-as nos componentes tamanho de mercado, distribuição de mercado e competitividade. O tamanho de mercado mostrou-se positivo nos três segmentos analisados, o que demonstra que a expansão da demanda mundial de soja e derivados foi fator fundamental para o crescimento das exportações brasileiras. O efeito distribuição de mercado foi negativo, o que indica que existem ineficiências nos canais de comercialização externa da agroindústria brasileira de soja. A competitividade, por sua vez, foi positiva apenas para as exportações de soja em grão. Contudo, destaca-se que o impacto positivo da competitividade no segmento de soja em grão mais que compensou em valores monetários, os impactos negativos nos segmentos de farelo e óleo. Dessa forma, políticas governamentais que melhorem a infra-estrutura e, conseqüentemente, reduzam os custos são necessárias para melhora da competitividade nos segmentos de farelo e óleo de soja.
\end{abstract}

Palavras-chave: Constant-Market-Share, competitividade, exportações, soja, Brasil.

\footnotetext{
${ }^{1}$ Recebido em 27/05/2004. Aceito em 28/07/2004.

${ }^{2}$ Doutorando em Economia Aplicada pelo Departamento de Economia Rural da UFV e bolsista da CAPES. Email: martinsfigueiredo@yahoo.com.br.

${ }^{3}$ Professor do Departamento de Economia Rural da UFV. E-mail: mlsantos@ufv.br.

${ }^{4}$ Professora do Departamento de Economia Rural da UFV. E-mail: vslirio@ufv.br .
} 


\section{Introdução}

O Brasil é o segundo maior produtor e exportador de soja do mundo. Diante dessas circunstâncias, a maneira como o país toma suas decisões torna-se questão essencial à manutenção e, ou, expansão de sua participação no mercado internacional de soja e derivados. De acordo com dados da Food and Agriculture Organization - FAO, as participações do Brasil no valor das exportações mundiais totais de soja em grão, farelo e óleo, em 2002, foram de $27,7 \%, 26,9 \%$ e 20,2\%, respectivamente.

Apesar da expansão das exportações brasileiras do complexo agroindustrial da soja na década de 1990, a participação do Brasil no mercado externo de farelo e óleo de soja vem sendo reduzida, de forma significativa, a partir de 1996. Na Tabela 1, observa-se nítida elevação da parcela média das exportações brasileiras do segmento de soja em grão, do subperíodo de 1990 a 1996 para o subperíodo de 1997 a 2002. Já nos segmentos de farelo e óleo de soja é observado o inverso, ou seja, o Brasil está perdendo participação no valor das exportações mundiais, com queda em seu market-share de $31,2 \%$ para $26,2 \%$ e de $20,0 \%$ para $16,6 \%$, respectivamente.

Tabela 1 - Participação média das exportações brasileiras no valor das exportações mundiais totais, nos subperíodos de 1990 a 1996 e de 1997 a 2002

\begin{tabular}{cccc}
\hline Média no período & Grão & Farelo & Óleo \\
\hline $90 / 96$ & 12,6 & 31,2 & 20,0 \\
$97 / 02$ & 24,2 & 26,2 & 16,6 \\
Variação (\%) & 92,1 & $-16,0$ & $-17,0$ \\
\hline
\end{tabular}

Fonte: FAO (2004) - Elaborado pelos autores. 
Essa expansão das exportações do segmento de soja em grão, em detrimento das exportações dos segmentos de farelo e óleo de soja, pode ser atribuída a diversos fatores, entre os quais se destacam: a) Adoção da Lei Kandir, que isentou do Imposto Sobre Circulação de Mercadorias e Serviços (ICMS) as exportações de produtos primários e semi-elaborados; b) Pequena escala das unidades esmagadoras nacionais em relação aos concorrentes, principalmente em relação à Argentina; c) Precária infra-estrutura de transporte e portuária, com relevantes impactos nos custos das esmagadoras nacionais, etc.

O Custo Brasil também foi considerado por Lazzarini e Nunes (1998) como fator determinante da competitividade da soja brasileira, em relação à dos Estados Unidos e da Argentina. No conjunto de ineficiências englobadas na estrutura do Custo Brasil, Wilkinson (2002) apontou os custos de transporte e portuários como os principais redutores da competitividade da soja brasileira no segmento pós-porteira. Além disso, a postura comercial da Argentina, com orientação estratégica para a comercialização de processados, também contribui para esse crescimento desfavorável às exportações brasileiras de derivados de soja, principalmente, porque as safras desses países ocorrem, basicamente, no mesmo período do ano, sendo, conseqüentemente, concorrentes na comercialização.

Diante desses problemas enfrentados pelo complexo agroindustrial da soja e de sua importância na pauta de exportações brasileiras, surgem alguns questionamentos como: a) Qual o comportamento da competitividade das exportações brasileiras de soja? b) Será a competitividade o fator responsável pelo aumento da participação da agroindústria brasileira de soja no comércio internacional? A importância dessas questões torna-se mais perceptível ao considerar a geração de divisas do complexo soja, que, na década de 1990, teve participação média de 8,6\% no valor das exportações brasileiras totais. Destaca-se, ainda, o peso dos segmentos de farelo e óleo nas exportações da agroindústria da soja, que chegou a 32,02\% e 15,18\%, em 2003, para um total de US\$ 8,12 bilhões em exportações (MDIC, 2004). Portanto, dian- 
te dessas considerações, torna-se de suma importância determinar os fatores que explicam a alteração da participação da agroindústria da soja brasileira no comércio internacional. Particularmente, pretende-se analisar a competitividade brasileira nas exportações de cada segmento da agroindústria de soja, no comércio internacional.

\section{Metodologia}

\subsection{Modelos de market-share}

Os trabalhos baseados em modelos de market-share visam avaliar a participação de um país ou região no fluxo mundial ou regional de comércio e desagregar as tendências de crescimento das exportações e, ou, importações de acordo com seus determinantes. A maioria desses trabalhos de market-share constitui-se de estudos exploratórios da evolução das exportações e suas causas, relacionadas com fatores estruturais e com a competitividade do país ou região de estudo (Carvalho, 1995).

Diversos trabalhos utilizaram o modelo Constant-Market-Share (CMS) para analisar a evolução da comercialização externa de produtos importantes para a pauta de exportação brasileira, aplicados tanto aos produtos agrícolas como aos industriais. Dentre eles, destacam-se os de Horta (1983), Gonçalves (1987), Carvalho (1995), Stalder (1997) e Batista (2002).

A idéia básica do modelo, segundo Leamer e Stern (1970), é de que a participação de um país no comércio internacional permanece constante no tempo. As alterações na participação dos países e, ou, regiões no comércio internacional são explicadas pela competitividade, associada aos preços relativos. Considerando-se que a relação de preços determina a escolha dos países importadores entre produtos similares de origem distinta, a equação de demanda, diferenciada por origem, desse mercado 
consumidor por um produto advindo de dois países exportadores, concorrentes no mercado internacional, pode ser escrita da seguinte maneira:

$$
\frac{q_{1}}{q_{2}}=f\left(\frac{p_{1}}{p_{2}}\right) \operatorname{com} f^{\prime}<0
$$

Segundo Leamer e Stern (1970), a equação (1) advém da relação básica da elasticidade de substituição, em que $q_{1}$ e $q_{2}$ são as quantidades vendidas pelos exportadores 1 e 2 , e $p_{1}$ e $p_{2}$, seus respectivos preços. A equação (1) pode ser representada na forma de market-share, multiplicando-a por $p_{1} / p_{2}$ e rearranjando os termos, de forma que:

$$
\frac{p_{1} q_{1}}{p_{1} q_{1}+p_{2} q_{2}}=\left\{1+\left[\frac{p_{1} * f\left(p_{1} / p_{2}\right)}{p_{2}}\right]^{-1}\right\}^{-1}=g\left(\frac{p_{1}}{p_{2}}\right) \operatorname{com} g^{\prime}<0 .
$$

A equação (2) implica que o market-share do país 1 permanecerá constante, se não houver alterações nos preços relativos $\left(p_{1} / p_{2}\right)$, sendo esse o princípio do modelo $\mathrm{CMS}$, ou seja, que a participação do país 1 permanece constante de um período de tempo para outro. Segundo Carvalho (1995), a estrutura das exportações de um país pode afetar sua competitividade mesmo na ausência de alterações em sua competitividade relativa. As exportações podem, por questão de prioridade, estar concentradas em regiões de crescimento mais acelerado e vice-versa, ou concentradas em produtos cuja demanda está crescendo rapidamente. Por isso, um modelo CMS mais completo deve incorporar tanto a diferenciação por origem como a diferenciação por mercadoria e destino.

Para representar matematicamente esses efeitos, Leamer e Stern (1970) propuseram três níveis de desagregação para análise das exportações usando o modelo CMS. No primeiro nível de análise, as exportações não 
são diferenciadas por mercadoria ou região, isto é, pressupõe-se que o país A exporte apenas uma mercadoria para um único mercado; no segundo, o modelo CMS é apresentado de forma mais realista, pois se admite que a pauta de exportações dos países seja diversificada, ou seja, composta por um conjunto de diversos produtos. No terceiro nível de análise, a desagregação do modelo CMS considera tanto a diferenciação por tipo de mercadoria comercializada quanto por países ou regiões de destino ( $j$ ). Dessa maneira, o modelo é escrito da seguinte forma:

$$
X_{i j}^{(I I)}-X_{i j}^{(I)}=\Delta X_{i j} \equiv\left[r_{i j} X_{i j}\right]+\left\lfloor X_{i j}^{(I I)}-X_{i j}^{(I)}-r X_{i j}^{(I)}\right\rfloor,
$$

em que $X_{i j}^{(I)}$ é o valor das exportações da mercadoria (i) do país A para o país ou região $(j)$, no período (I); $X_{i j}^{(I I)}$, valor das exportações da mercadoria ( $i$ ) do país A para o país ou região (j), no período (II); e $r_{i j}$, mudança percentual nas exportações mundiais da mercadoria $(i)$ para o país ou região (j), do período (I) para o período (II). Desagregando os termos da identidade (3) e agrupando todas as mercadorias e regiões de destino, obtém-se:

(a) (b)

$\Delta X_{i j} \equiv\left[r X_{\bullet \bullet}^{(I)}\right]+\left[\sum_{i}\left(r_{i}-r\right) X_{i \bullet}^{(I)}\right]+\left[\sum_{i} \sum_{j}\left(r_{i j}-r_{i}\right) X_{i j}^{(I)}\right]+\left[\sum_{i} \sum_{j}\left(X_{i \bullet}^{(I I)}-X_{i \bullet}^{(I)}-r_{i} X_{i \bullet}^{(I)}\right)\right]$

Essa identidade mostra que mudanças positivas ou negativas nas exportações do país A resultam da soma de quatro efeitos, representados pelos termos sobrepostos na identidade (4): a) Variação das exportações do país A, devido ao crescimento da demanda mundial; b) Crescimento resultante da combinação de mercadorias que compõem a pauta de exportação do país A (Quando o termo $\left(r_{i}-r\right)$ for positivo, indicará que as exportações do país A estão mais concentradas em bens cujos mercados apresentem taxas de crescimento mais favoráveis do que a média 
mundial); c) Variação nas exportações devido à distribuição das exportações do país A entre regiões com crescimento em ritmo mais ou menos acelerado; e d) Efeito competitividade que reflete a diferença entre o crescimento efetivo das exportações e o crescimento que ocorreria nas exportações do país A, mantendo o mesmo percentual de exportação de cada produto para cada região de destino, do período (I) para o período (II).

Stalder (1997) declarou que, se a demanda de exportação for descrita pela equação (1), a competitividade computada por resíduo dependerá apenas dos preços relativos $p_{1} / p_{2}$ entre os diferentes ofertantes e concorrentes no mercado internacional. $\mathrm{O}$ efeito competitividade, quando negativo, isto é, $(\mathrm{d}<0)$, refletirá o fracasso do país em manter seu market-share e significará que os preços dos produtos desse país se tornaram maiores, relativamente aos preços dos seus concorrentes.

Entretanto, a associação do efeito competitividade apenas com as variações dos preços relativos mostra que as variações no market-share dos países competidores no mercado internacional dependem da sua competitividade via preços. Segundo Stalder (1997), em relação a esse aspecto surgem críticas ao modelo CMS, devido à incapacidade de mensurar o grau de influência de outros fatores, além dos preços relativos, que possivelmente podem estar compreendidos no resíduo de competitividade.

Leamer e Stern (1970) apontaram alguns desses fatores como de maior relevância: 1) Diferenciação devido à melhora na qualidade; 2) Eficácia no desenvolvimento de novos produtos; 3) Aumento na eficiência do marketing ou aprimoramento dos mecanismos de financiamentos das operações de venda; e 4) Capacidade para atender prontamente às encomendas dos importadores.

Segundo Leamer e Stern (1970), análises das séries temporais da demanda dificilmente permitem isolar o efeito desses fatores. O que acon- 
tece, na realidade, é que alguns fatores têm influência no preço de oferta das exportações; por isso, ao considerar que a competitividade é determinada pelos preços relativos, o efeito competitividade calculado pelo modelo CMS torna-se sensível a variações dos fatores relacionados com oferta de exportações dos países competidores.

A vantagem dessa abordagem, com relação à análise tradicional da demanda, é que ela proporciona melhor orientação estratégica para o governo e o setor privado na alocação de esforços exportadores em mercadorias e, ou, mercados com maior potencial de expansão. Para Carvalho (1995), essa possibilidade surge da eficácia do método CMS em melhor visualizar as tendências e perspectivas dos mercados importadores e da participação dos concorrentes nestes.

A versão do modelo Constant-Market-Share, que será aplicada neste trabalho, foi ilustrada pela identidade (4). Entretanto, para sua aplicação foram feitas algumas adaptações, semelhantes àquelas realizadas por Stalder (1997). A diferença básica existente entre o trabalho deste autor e a formulação aplicada nesta pesquisa está na variável de análise, que, neste caso, foi o valor, e não o volume das exportações e importações. A justificativa para essa diferença baseia-se em Leamer e Stern (1970), que argumentaram que a competitividade é determinada pelos preços relativos; assim, para desagregação dos seus componentes, o valor das exportações e importações torna-se mais adequado em relação ao volume.

\subsubsection{Operacionalização do modelo CMS}

A seleção das regiões de destino foi realizada por meio do peso das importações desses países no total da demanda mundial de cada mercadoria (i), no período de 1990 a 2002; assim, foram construídos três grupos que continham dez países importadores e o Resto do Mundo, respectivamente, para os segmentos de soja em grão, farelo e óleo. No grupo I, do segmento de soja em grão, foram considerados os seguintes 
países importadores (j): Alemanha, China, Espanha, França, Itália, Japão, México, Países Baixos, Portugal, Reino Unido e Resto do Mundo. No grupo II, formado para o segmento de farelo de soja, foram selecionados Alemanha, Bélgica, China, Espanha, França, Indonésia, Itália, Países Baixos, Tailândia, Reino Unido e Resto do Mundo. No grupo III, do segmento de óleo de soja, foram selecionados Alemanha, Bangladesh, China, Egito, Índia, Irã, Marrocos, México, Países Baixos, Paquistão e Resto do Mundo.

O modelo CMS foi aplicado sobre a média do valor das exportações brasileiras do período (I), que compreende os anos de 1990 a 1996, no período (II), que compreende os anos de 1997 a 2002. Os procedimentos para aplicação do modelo seguem a desagregação anterior, com 11 regiões de destino, e consideram cada mercadoria separadamente. A opção por analisar cada mercadoria de forma distinta surge do objetivo de computar a competitividade do Brasil em cada segmento da cadeia produtiva da soja.

\subsubsection{Fonte de dados e variáveis}

Os dados utilizados nesta pesquisa foram obtidos na FAO e no Ministério da Agricultura, Indústria e Comércio Exterior (MDIC), mediante Secretaria de Comércio Exterior (SECEX). O MDIC forneceu séries mensais de valor das exportações, desagregadas por todos os países de destino e por todos os derivados da cadeia agroindustrial da soja. Os dados foram agrupados para os segmentos grão, farelo e óleo de soja, de acordo com a Nomenclatura Comum do Mercosul (NCM). Na construção do modelo CMS, o valor das exportações brasileiras por países de destino foi agregado para o período de 1990 a 2002. 


\section{Resultados e discussão}

\subsection{Análise de market-share e competitividade das exportações brasileiras}

Os resultados da análise de market-share são apresentados, separadamente, entre os segmentos de grão, farelo e óleo de soja, conforme mencionado no item 2.2.1., do tópico Metodologia. A análise permite: a) Verificar a atuação de Brasil nos mercados importadores selecionados, discriminando a participação das exportações brasileiras em cada um desses mercados, para cada segmento da cadeia agroindustrial da soja ${ }^{5}$; b) Computar e comparar as variações potenciais e efetivas no valor das exportações do Brasil; e c) Definir e comparar os principais componentes causadores das discrepâncias (negativas ou positivas) entre as exportações efetivas e potenciais do Brasil, desagregando-as entre os componentes: tamanho de mercado, distribuição de mercado e competitividade.

\subsubsection{Exportações de soja em grão}

Ao contrapor os resultados do modelo CMS, apresentados na Tabela 2, para os subperíodos 1990/96 e 1997/02, percebe-se que a participação média do Brasil no total mundial comercializado subiu de 10,8\% para 21,1\%. O expressivo crescimento das exportações totais do Brasil, em relação ao total das exportações mundiais, teve como reflexo o aumento da participação do Brasil em todos os mercados desagregados no modelo CMS, cabendo destacar a expansão das exportações para a China, que, basicamente, inexistiam. A participação média do Brasil passou de $0,1 \%$ para $15,7 \%$ nas importações desse mercado.

${ }^{5}$ Os resultados referentes ao item (a) são expostos no Apêndice A. 


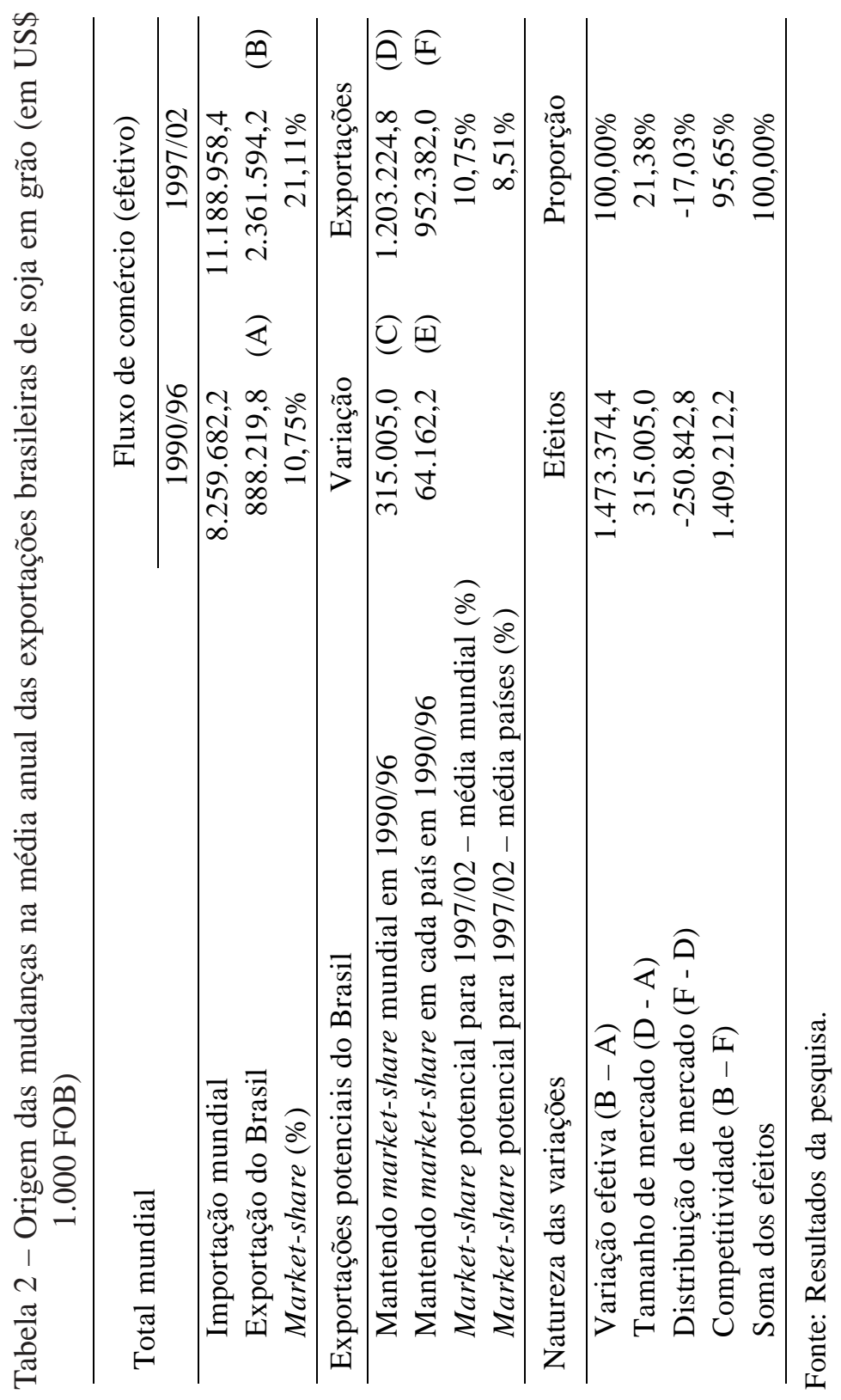


Na Tabela 2 há também indicação clara da importância da desagregação por destino, ao analisar os determinantes dos fluxos comerciais, devido à sensibilidade do modelo CMS aos diferentes níveis de desagregação. Isso pode ser constatado nas estimativas da variação potencial das exportações do Brasil, que foram de aproximadamente US\$315,0 milhões, para nenhuma desagregação, isto é, considerando-se constante a participação calculada das exportações totais de soja em grão do Brasil no mercado mundial para 1990/96. Já para o nível de desagregação de 11 regiões adotado neste trabalho, esse valor é de apenas US\$ 64,1 milhões. Dessa maneira, pode-se perceber que, se o Brasil mantiver constante sua participação em cada mercado importador individual, ele obterá em suas exportações um desempenho diferente do que se mantiver constante sua participação média no comércio mundial.

A parte final da Tabela 2 contém os determinantes do acréscimo das exportações médias do Brasil, nos subperíodos 1990/96 e 1997/02, por meio dos quais o incremento no valor das exportações brasileiras foi desagregado e dimensionado, de acordo com sua natureza, nos efeitos tamanho de mercado, distribuição de mercado e competitividade. Dentre esses determinantes, o tamanho de mercado e a competitividade atuaram de forma positiva na expansão das exportações brasileiras; cada um desses efeitos teve participação média de $21,38 \%$ e 95,65\%, respectivamente, na variação efetiva das exportações brasileiras totais.

O efeito distribuição de mercado foi negativo, induzindo à redução das exportações do Brasil em 17,03\%, porém a dimensão dos dois outros efeitos, principalmente do efeito competitividade, mais que o compensou. Esse resultado pode estar associado também às distorções geradas pela política agrícola dos EUA, pautada em subsídios diretos à produção e à exportação de soja. De acordo com dados da Confederação Nacional da Agricultura (CNA), os subsídios totais concedidos pelo governo norte-americano à cadeia produtiva (CPA) da soja aumentaram de US\$ 109,0 milhões, em 1993, para cerca de US\$ 2,84 bilhões, em 2000. Esses subsídios podem gerar distorções no comércio internacional, promovendo aumentos artificiais na oferta mundial, capazes de induzir reduções 
nos níveis de preços internacionais, tornando menos vantajoso para os concorrentes colocar seus produtos em mercados com demandas relativamente mais elásticas, ou impossibilitando-os de fazê-lo.

A diferença entre o valor das exportações efetivamente comercializadas e o valor das exportações esperadas, apresentados na Tabela 2, respectivamente nos itens B e D, relaciona-se, segundo Konandreas e Hurtado (1978), citados por Stalder (1997), com fatores naturais e artificiais. Na classe dos naturais estão os fatores estruturais, característicos de cada país, como disponibilidade de terras agricultáveis, dimensão territorial e infra-estrutura de transportes, que exercem influência positiva ou negativa nos custos relativos dos países exportadores. Na outra classe estão os fatores artificiais, que, por sua vez, resultam de acordos preferenciais bilaterais, da formação de blocos regionais ou da adoção de medidas protecionistas, sobre os quais os países exportadores que competem entre si têm pouca ou nenhuma influência.

\subsubsection{Exportações de farelo de soja}

Conforme dados da Tabela 3, houve redução na participação média do Brasil no mercado mundial de farelo de soja, de $26,21 \%$ para $22,34 \%$, do subperíodo 1990/96 para 1997/02. A atuação do país nos principais mercados importadores de farelo de soja não foi expressiva, dada a redução significativa de sua participação nas importações de Espanha, Itália e Países Baixos. A expansão das exportações brasileiras nos demais mercados não foi suficiente para repor as perdas de participação nos mercados discriminados, conforme item 2.2.1., do item de Metodologia, o que indica que o crescimento médio das exportações brasileiras foi mais lento do que o da demanda mundial. 


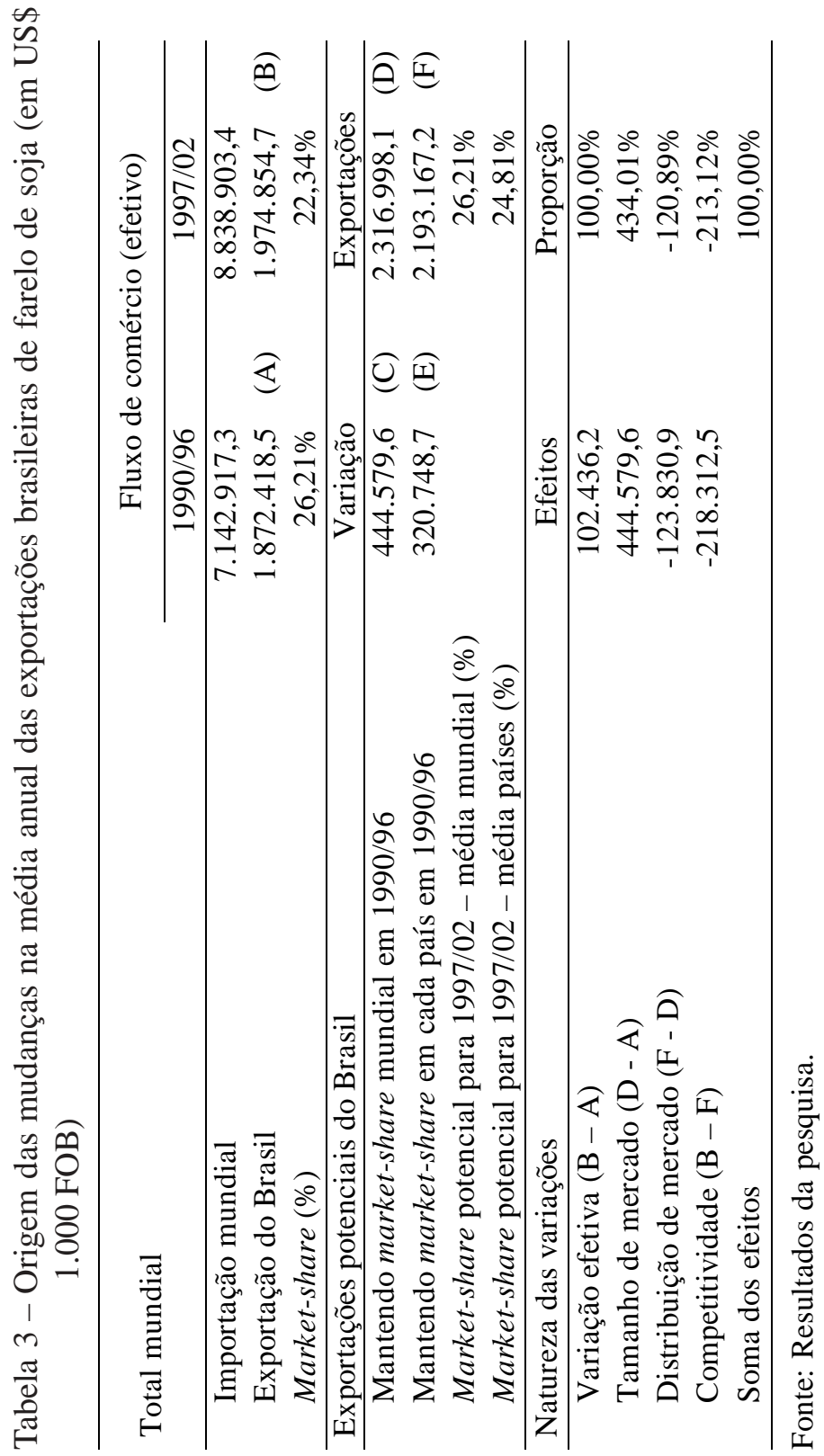


Os resultados apresentados na Tabela 3 mostram que o Brasil perdeu competitividade no segmento de exportação de farelo de soja, além de não ter acompanhado o crescimento de mercado dos principais importadores. Todavia, o incremento das exportações brasileiras, induzido pelo crescimento da demanda mundial, foi suficiente para contrabalançar os efeitos distribuição de mercado e competitividade, que foram negativos, gerando um incremento efetivo nas exportações brasileiras de US\$102,4 milhões, no subperíodo 1997/02.

A queda na competitividade das exportações de farelo de soja no Brasil e o não-acompanhamento da expansão da demanda dos principais mercados importadores desse produto têm como provável explicação a combinação dos seguintes acontecimentos: a) Aumento do consumo interno de farelo de soja, devido à substituição de componentes de origem animal por componentes de origem vegetal na fabricação de rações; e b) Crescimento dos rebanhos brasileiros, impulsionado pela grande expansão das exportações de carnes.

Segundo Martins (2003), a produção de carne de frango atingiu, em 2002, cerca de 7,45 milhões de toneladas, superando à de carne bovina, que foi de 6,9 milhões de toneladas, nesse mesmo ano. As exportações de carne bovina passaram de 192,8 mil toneladas, em 1998, para 590,7 mil toneladas, em 2002. Já as exportações brasileiras de carne de frango atingiram 1,6 milhão de toneladas em 2002 , volume $76,6 \%$ superior ao verificado no ano de 2000. Rosário (2001) argumentou também que a taxa de crescimento médio das exportações de suínos, na década de 1990, situou-se em torno de $17,92 \%$. O crescimento expressivo do setor de carnes aqueceu o segmento interno de farelo de soja, reduzindo a capacidade brasileira de gerar excedentes exportáveis.

\subsubsection{Exportações de óleo de soja}

O comportamento das exportações de óleo de soja aponta a redução do market-share do Brasil. Na Tabela 4, a participação esperada do Brasil, 
em relação ao comércio internacional de óleo de soja, reduziu de 19,75\% para $17,54 \%$, do subperíodo 1990/96 para 1997/02. Considerando a desagregação proposta no modelo CMS, a participação média efetivamente ocorrida foi de $16,29 \%$, isto é, menor que a esperada, o que sugere que o setor exportador da agroindústria brasileira de soja tem se especializado nas exportações do produto in natura, em relação aos produtos derivados. 


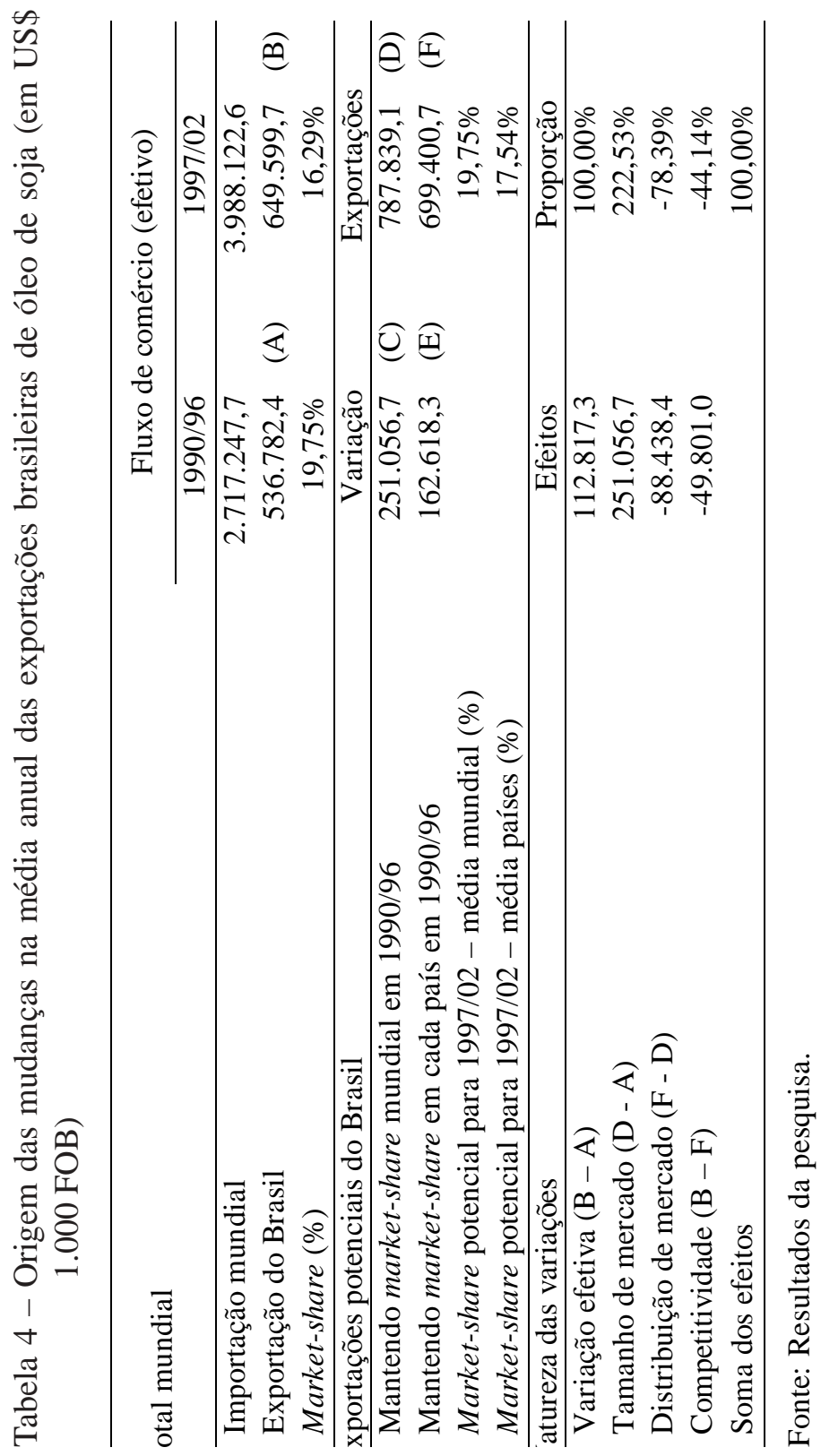


Os resultados da Tabela 4 mostram que a exportação efetiva do Brasil, no subperíodo 1997/02, deveria situar-se entre US\$ 699,4 e US\$787,8 milhões, de acordo com o método de participação constante de mercado. No entanto, constata-se que a exportação média do Brasil foi de apenas US\$ 649,6 milhões, gerando um crescimento efetivo de US\$112,8 milhões, abaixo do valor mínimo esperado de US\$162,6 milhões.

Esse crescimento se deu pela grande expansão da demanda mundial de óleo de soja, que atingiu uma média de 47\%, do subperíodo 1990/96 para 1997/02. O impacto médio das variações da demanda mundial sobre as exportações brasileiras de óleo de soja foi mensurado em US\$251,0 milhões, valor que corresponde a $222,53 \%$ do crescimento efetivo.

O baixo crescimento das exportações brasileiras de óleo de soja se explica pela queda na competitividade brasileira nesse segmento e pelo efeito distribuição de mercado. Esses efeitos promoveram impactos negativos, gerando uma compensação no crescimento das exportações brasileiras induzido pelo crescimento da demanda mundial. Os impactos foram estimados, de acordo com o método de market-share constante, em US\$ 49,8 milhões e US\$ 88,4 milhões para os respectivos efeitos competitividade e distribuição de mercado. Esse último efeito mostra que o Brasil tem encontrado dificuldade em exportar seus excedentes para os mercados analisados, fato naturalmente compreensível quando se considera a estratégia comercial dos países da UE, que visam importar o produto in natura para depois efetuar o esmagamento.

Segundo Lazzarini e Nunes (1998), a queda na competitividade brasileira no segmento de óleo, bem como no segmento de farelo de soja, pode estar associada a outros determinantes, além dos elevados níveis de consumo interno desses produtos. Dentre os determinantes enumerados pelos autores, destacaram-se os seguintes: a) Baixa capacidade de esmagamento das unidades processadoras do Brasil, quando comparada à capacidade de esmagamento das indústrias localizadas nos países concorrentes, especialmente na Argentina; b) Custos de transporte brasileiro ainda elevados, principalmente para óleo de soja, que possui custos de 
transporte mais altos do que o grão e farelo de soja, devido a características intrínsecas do próprio produto; e c) Elevada carga tributária, com impactos diretos nos custos das processadoras, reduzindo a rentabilidade da operação.

\section{Conclusões}

A análise de market-share permitiu desagregar as variações reais no valor das exportações de soja e derivados do Brasil entre os componentes: tamanho de mercado, distribuição de mercado e competitividade. $\mathrm{O}$ efeito tamanho de mercado foi positivo, o que indica que o dinamismo do comércio internacional com aquecimento da demanda mundial foi preponderante para a expansão das exportações agroindustriais de soja desse país.

O efeito distribuição de mercado foi negativo, o que implica que houve esforços de comercialização com países importadores cuja demanda reduziu ou cresceu abaixo da média mundial, particularmente nos segmentos de farelo e óleo de soja.

Enquanto isso, constataram-se aumento na competitividade brasileira no segmento de soja em grão e redução nos segmentos de farelo e óleo de soja. Cabe destacar que, de acordo com o modelo CMS, o impacto positivo da competitividade no segmento de soja em grão mais que compensou, em valores monetários, os impactos negativos nos segmentos de farelo e óleo de soja; assim, foi possível inferir que o incremento na competitividade contribuiu para elevar a participação da agroindústria brasileira de soja no mercado internacional. Esses resultados sugerem que a adoção de políticas públicas, com vistas em melhorar a infra-estrutura de transportes, e a redução da carga tributária e de incentivos à expansão das escalas de produção das esmagadoras nacionais são importantes para elevar a competitividade do Brasil nos segmentos de processados. 
Quanto às dificuldades encontradas, destaca-se a fragilidade dos métodos utilizados, devido às fortes pressuposições simplificadoras para viabilizar sua utilização, como a hipótese de oferta mundial perfeitamente elástica, adotada nas estimativas dos modelos de market-share. Além disso, na análise de market-share evidenciam-se os problemas gerados pela agregação dos períodos e dos mercados, que possivelmente restringem o alcance dessas conclusões.

\section{Referências bibliográficas}

BATISTA, J.C. Desvalorização cambial e as exportações brasileiras para os Estados Unidos. Brasília: FUNCEX, 2002. [11 fev. 2004]. (www.funcex.com.br/bases/70-Exportacoes-JCB.pdf).

CARVALHO, F.M.A. O comportamento das exportações brasileiras e a dinâmica do complexo agroindustrial. Piracicaba: ESALQ, 1995. 126 p. Tese (Doutorado em Economia Agrária) - Escola Superior de Agricultura Luiz de Queiroz, 1995.

CONFEDERAÇÃO NACIONAL DA AGRICULTURA - CNA. The support programmes for US soybean producers: their actionable inconsistencies to WTO agreements and the serious losses to Brazil. [22 abr. 2004]. (http://www.cna.org.br/Informa\%E7\%F5es02/ $\begin{array}{lllllllll}\mathrm{S} & \mathrm{e} & \mathrm{t} & \mathrm{e} & \mathrm{m} & \mathrm{b} & \mathrm{r} & \mathrm{o} & /\end{array}$ TRABALHO\%20SOJA\%20CONTENCIOSO\%20OMC.pdf).

FOOD AND AGRICULTURE ORGANIZATION OF THE UNITED NATIONS - FAO. FAOSTAT Database. [20 jan. 2004]. (http:// apps.fao.org/).

GONÇALVES, R. Competitividade internacional, vantagem comparativa e empresas multinacionais: o caso das exportações brasileiras de manufaturados. Pesquisa e Planejamento Econômico, Rio de Janeiro, v. 17, n. 2, p. 411-436, ago. 1987.

HORTA, M.H.T. Fontes de crescimento das exportações brasileiras na 
década de 70. Pesquisa e Planejamento Econômico, v. 2, n. 13, p. 507-542, ago. 1983.

LAZZARINI, S.G., NUNES, R. Competitividade do sistema agroindustrial da soja. São Paulo, SP: PENSA/USP, 1998. [28 jan. 2004]. (http://www.fia.com.br/ pensa/pdf/relatorios/ipea/ Vol V Soja.PDF).

LEAMER, E.E., STERN, R.M. Quantitative international economics. Chicago: Aldine Publ., 1970. p. 171-183.

MARTINS, S.S. Situação e perspectivas do mercado de frango de corte. Informações Econômicas, São Paulo, v.33, n. 7, p. 70-72, jul. 2003.

MINISTÉRIO DA AGRICULTURA, INDÚSTRIA E COMÉRCIO EXTERIOR - MDIC. Estatísticas de exportação e importação brasileira, 1989 a 2004. [20 jan. 2004]. (http:// aliceweb.desenvolvimento.gov.br/).

RICHARDSON, J.D. Constant-market-shares analysis of export growth. Journal of International Economics, v. 1, p. 227-239, July 1971.

ROSÁRIO, J.B.F. Competitividade de produtos "in natura" e processados do Brasil no comércio exterior. Viçosa, MG: UFV, 2001. 114 p. Tese (Mestrado em Economia Rural) - Universidade Federal de Viçosa, 2001.

STALDER, S.H.G.M. Análise da participação do Brasil no mercado internacional de açúcar. Piracicaba, SP: ESALQ, 1997. 121 p. Dissertação (Mestrado em Economia Aplicada) - Escola Superior de Agricultura Luiz de Queiroz, 1997.

WILKINSON, J. Estudo da competitividade de cadeias integradas no Brasil: impactos das zonas de livre comércio. Campinas, SP: UNICAMP-IE-NEIT, 2002. [22 ago. 2003]. (http://www.cinrs.org.br/ download/NT2\%20Biotec Agronegocios.doc). 


\begin{abstract}
The objective of this work is to determine factors that explain the alteration of the participation of the Brazilian soybean agro-industry and industry in the international trade. Particularly, it intends to analyze the Brazilian competitiveness in the exports of each segment of the soybean agro-industry. For this, the ConstantMarket-Share (CMS) model was used, through which, the discrepancies were computed in the potential and effectual variation of the Brazilian exports of soybeans, soybean meal and oil, disaggregating them in these components: market size, market distribution and competitiveness. The market size was shown positive for the three analyzed segments, demonstrating that the expansion of the world demand of soybean and its by-products it was fundamental factor to the growth of the Brazilian exports. The effect market distribution was negative, indicating that there are inefficiencies in the commercialization channels of the Brazilian of soybean agro-industry. The competitiveness, for its time, was only positive for the soy exports in grain. However, it stands out that the positive impact of the competitiveness, in the soy segment in grain compensated more in monetary values than the negative impacts in the soybean meal and oil segments. In that way, are necessary government politics that improve the infrastructure and, consequently, reduce the costs for improvement of the competitiveness in the soybean meal and oil segments.
\end{abstract}

Keywords: Constant-Market-Share, competitiveness, exports, soy, Brazil. 


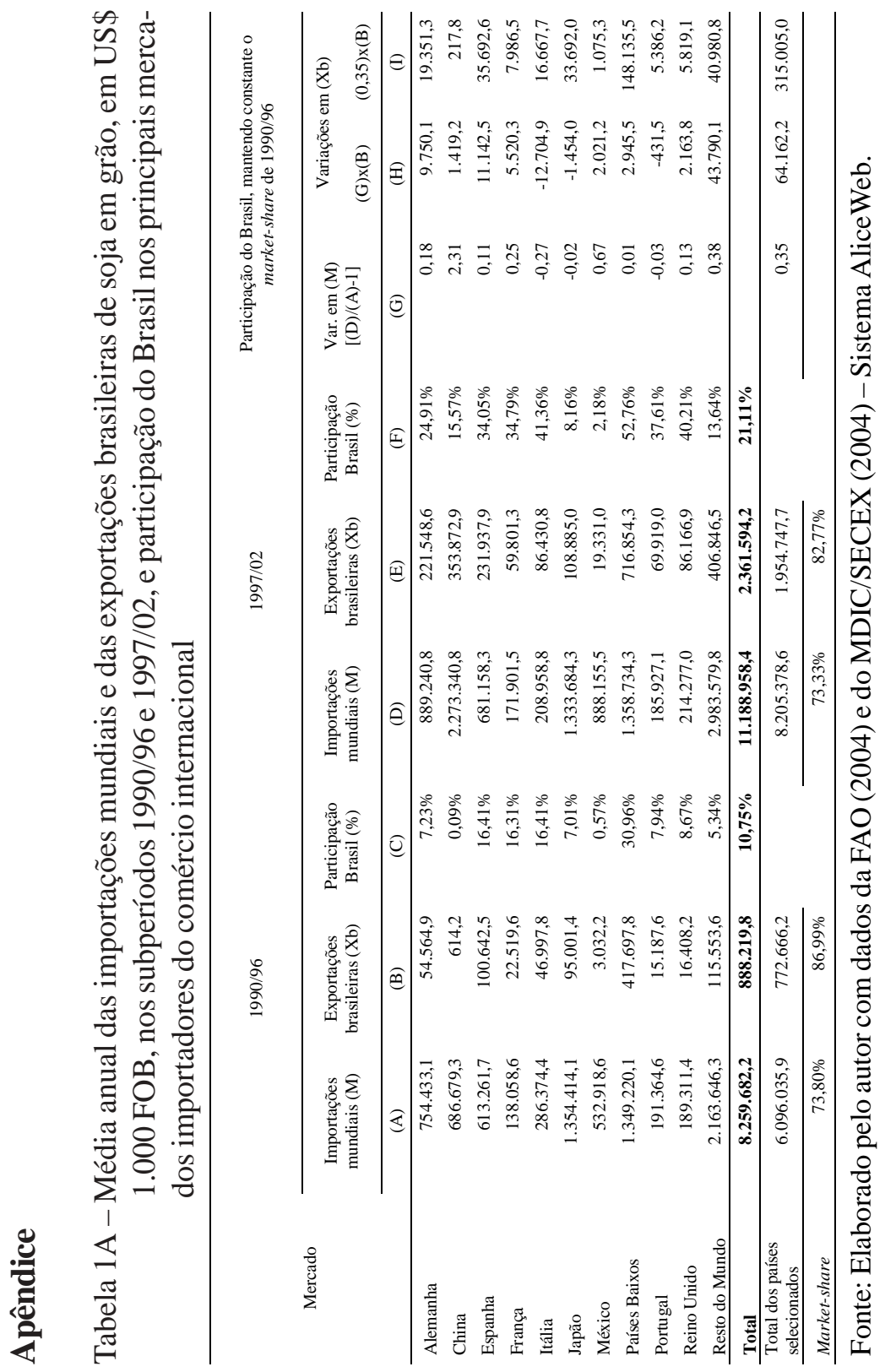




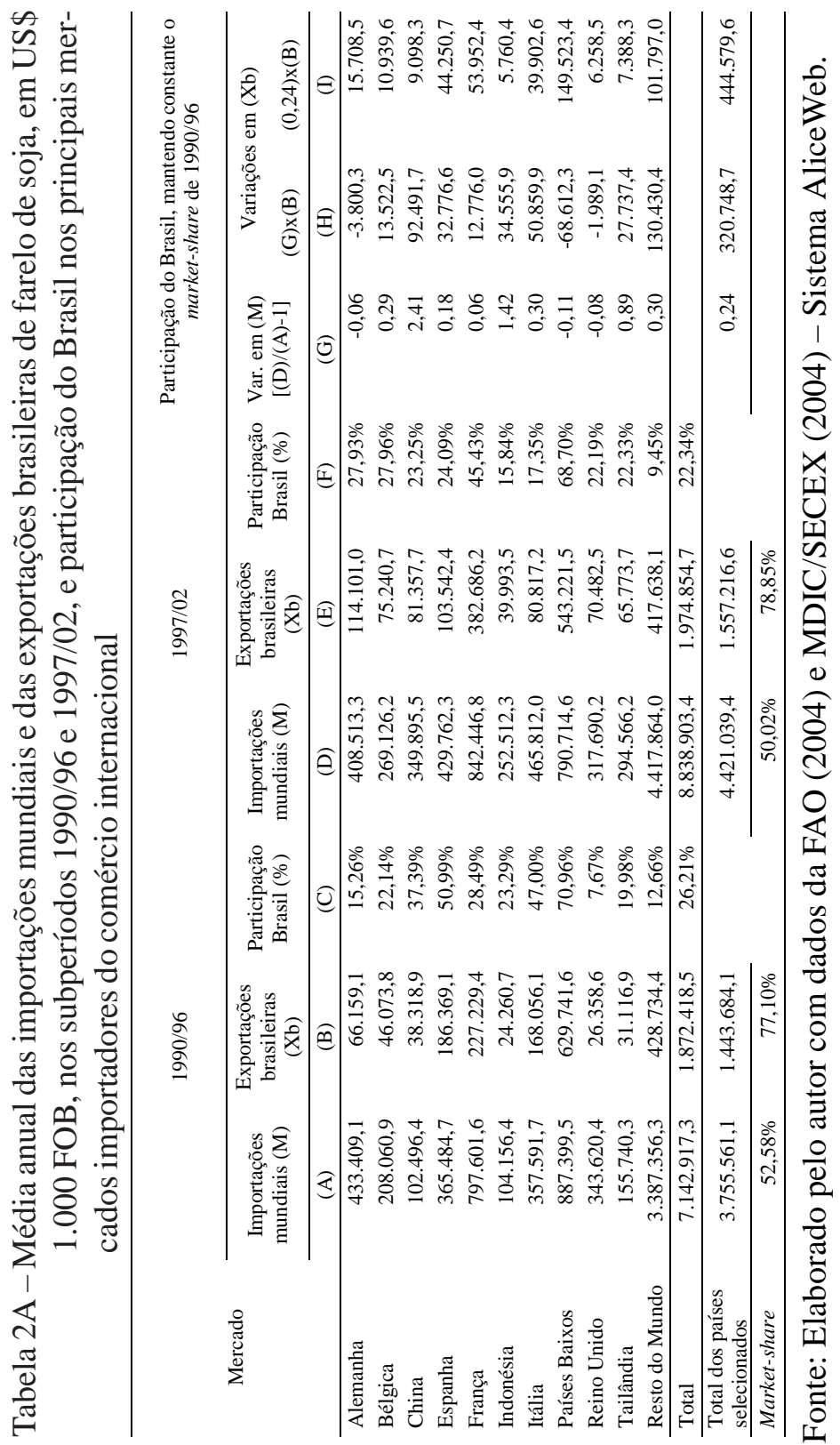




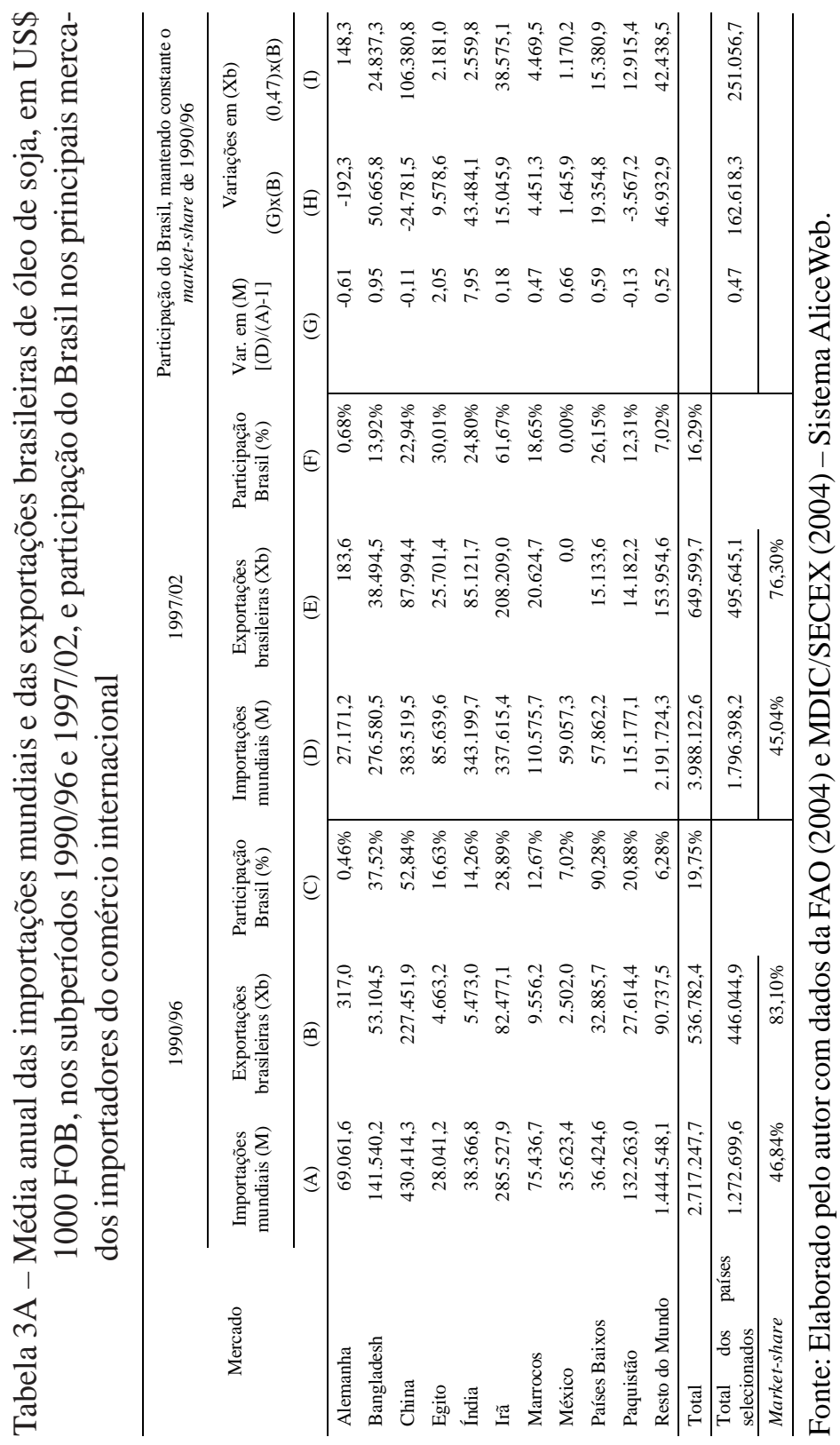


REVISTA DE ECONOMIA E AGRONEGÓCIO, VOL.2, N $N^{o} 3$ 